\title{
Significance of continuing audiovestibular practice during Covid-19 pandemic
}

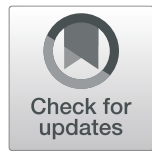

\author{
Oğuz Yilmaz (D), Dilara Bayazit@, Handan Yaman(D) and Berna Özge Mutlu(D)
}

\begin{abstract}
Background: We aimed to evaluate the significance of continuing audiovestibular practice during the Covid-19 pandemic in the audiology clinic of the university hospital.

Methods: The precautions, test procedures, and risk factors associated with the practice of audiology were evaluated. The number and diagnoses of the cases between 23 March and 23 May 2020 were also compared with the results of the same 2 months in 2019 in an attempt to evaluate the alterations in the audiology practice.

Results: The audiology practice has continued during the pandemic, and numerous audiovestibular tests like newborn hearing screening, pure tone and speech audiometry, auditory brainstem response (ABR) test, bedside vestibular assessment, videomystagmography (VNG), caloric test, vestibular evoked myogenic potential (VEMP), computerized dynamic posturography (CDP), video head impulse test (vHIT), intraoperative cochlear implant measurement, and postop cochlear implant fittings were performed. The number of tests has decreased significantly in the course of the pandemic $(p<0.01)$. No evidence of Covid-19 disease was detected in the audiology staff and patients. In general, no major risk was seen during testing under protective measures except for vestibular testing which induced vomiting and taking out the mask for lip reading during cochlear implant fitting in the elderly.

Conclusion: It is possible to perform audiovestibular tests during the Covid-19 pandemic by wearing necessary protective equipment and disinfecting the potential surfaces. Vomiting during vestibular tests, uncovering the nose and mouth for lip reading, and small-sized test cabins are the main risk factors of contamination in the audiology clinics.
\end{abstract}

Keywords: Covid-19, SARS-CoV-2, Audiology, Vestibular

\section{Bullet point summary}

The audiological test protocols of the hospital are presented.

Covid-19 pandemic has a negative impact on audiological services.

Vomiting and communication with lip reading may increase the risk of contamination.

The main risk factors and protection methods for possible pandemics in the future are defined.

\footnotetext{
*Correspondence: dryilmazoguz@gmail.com; oyilmaz@medipol.edu.tr Department of Audiology, Istanbul Medipol Mega University Hospital, Göztepe Mah. Metin Sk. Nu:4, Bağcilar, Istanbul, Turkey
}

\section{Background}

Since December 2019, when SARS-CoV-2 first emerged in Wuhan, China, coronavirus disease (Covid-19) has been a major world health problem in the form of a pandemic.

The risk of infection for health care professionals and patients in audiology laboratories is important. There is no vaccine or treatment for now. Social distancing or reducing interpersonal and community interaction is the main way to minimize disease transmission [1].

It is still unclear or controversial whether it is safe to perform elective audiological tests. Despite the decrease in the new cases of Covid-19, most of the audiology clinics still hesitate to perform elective audiological tests 
with concerns related to the safety of patients and physicians.

In this study, we aimed to evaluate the significance of continuing audiovestibular practice during the Covid-19 pandemic.

\section{Methods}

During the Covid-19 pandemic, between 23 March and 23 May 2020, the working protocol of the audiovestibular clinic of the university was evaluated. As a general regulation, at the entrance of the hospital, body temperatures of health care professionals, patients, and family members have been monitored using an infrared thermometer. Those who had a body temperature above 37.3 ${ }^{\circ} \mathrm{C} 9$ were referred to Covid-19 clinic of the same hospital.

Everybody entering the hospital including the hospital staff had to wear a surgical mask. In the waiting area of the audiology clinic, the rule of social distancing was applied. In the audiology clinic, in addition to the audiologist, only one of the family members was allowed to accompany a child being tested. No companion was allowed to enter the test room while testing an adult patient.

As a precaution, the number of audiology personnel was reduced by switching to the shift system. All the personnel had protective tools like masks (surgical or N95 type), gloves, and face shields. Hand washing is instructed after every test. Alcohol-based disinfectants were used for hand hygiene and cleansing the audiovestibular devices. All test devices and the contact surfaces in the rooms were cleaned with the same disinfectant 3 times a day. Disposable or sterilized electrodes or probes were used, if applicable. Otherwise, the equipment or cables were cleaned using disinfectants. The test interval between the patients was set to half an hour.

In newborn hearing screening, under normal circumstances, detection and intervention programs in Turkey have $24 \mathrm{~h}$ and first, third, and sixth month benchmarks. The newborn hearing screening of the babies who were born in the same hospital was done, and they are discharged. If the newborn was admitted to the neonatal intensive care unit or could not pass three successive hearing screenings, auditory brain stem response (ABR) and the other test batteries were performed. During the Covid-19 pandemic, the Ministry of Health restricted the performance of second hearing screening and clinical ABR testing. However, newborn hearing screening was continued.

On pure tone and speech audiometry, no trouble happened while putting on headphones and bone vibrators in the presence of surgical masks to the patients. The audiologist had to take out the mask during speech tests.
Sterile probes were used for each patient on tympanometry.

On ABR testing, the audiologist wore an N95 mask due to the small size of and absence of the ventilator in the test room and a long test procedure of 1 to $2 \mathrm{~h}$.

Regarding the cochlear implants $(\mathrm{CI})$, since the patients had negative PCR test result for Covid-19, and normal laboratory and radiological findings, the intraoperative measurements of CIs were done wearing N95 masks in the operation rooms. Postoperative CI fitting was done under the aforementioned protocols unless lip reading was necessary, in which the mask was taken out.

Vestibular tests were done under the aforementioned protocols. The goggle glasses were disinfected with alcohol-based disinfectants. The mask of the patient was taken out for a while in order to place the electrodes during vestibular evoked myogenic potentials (VEMP) testing. Water caloric, video head impulse test (vHIT), videonystagmography (VNG), and computerized dynamic posturography (CDP) were performed.

\section{Results}

During the Covid-19 pandemic, a significant decrease was encountered in the number of tests performed in the audiology clinic as a result of governmental regulations, social isolation rules, and hesitation of the patients to visit the audiology clinic in the hospital $(p<0.01)$ (Table 1).

Under normal circumstances, there were 5 audiologists and 2 audiometrists in the audiology clinic. During the period of the pandemic, 1 audiologist and 1 audiometrist worked in the clinic. All patients who were tested in the audiology department were seen by an ENT physician except for the newborns who were seen by pediatricians.

No evidence of Covid-19 disease was detected in the audiology staff as evidenced by their negative PCR testing and the absence of signs and symptoms of the disease. None of the patients was suspected of having Covid-19 according to history and absence of signs and symptoms of the disease like high fever and cough.

In general, no major risk was seen during testing under protective measures. However, one of the major risks encountered was during vestibular testing, in which 3 patients vomited during VNG tests. During CI fitting of the elderly patients, the audiologist had to take out the mask in order to overcome communication problems through lip reading.

\section{Discussion}

Covid-19 is an acute respiratory illness caused by SARS$\mathrm{CoV}-2$ infection [2]. This pandemic is a global public health emergency affecting millions of people worldwide.

Although the majority of people postponed their treatment during the pandemic, still, there are people who 
Table 1 The audiology clinic test numbers of 1-year interval during the Covid-19 pandemic

\begin{tabular}{llll}
\hline $\begin{array}{l}\text { Tests performed in } \\
\text { the audiology clinic }\end{array}$ & $\begin{array}{l}\text { Period 23 May to 23 March 2019, } \\
\text { no. of cases }\end{array}$ & $\begin{array}{l}\text { Period 23 May to 23 March 2020, } \\
\text { no. of cases }\end{array}$ & $\begin{array}{l}\text { Alteration between } \\
\text { the periods, (\%) }\end{array}$ \\
\hline Audiometry & 657 & 128 & 81 \\
Immitancemetry & 529 & 96 & 82 \\
ABR & 47 & 11 & 77 \\
A-ABR & 419 & 124 & 70 \\
VEMP & 31 & 3 & 90 \\
VNG & 48 & 9 & 81 \\
Caloric test & 17 & 9 & 47 \\
VHIT & 14 & 1 & 93 \\
CDP & 6 & 0 & 100 \\
Play audiometry & 22 & 0 & 100 \\
OAE & 17 & 2 & 88 \\
Tinnitus assessment & 2 & 7 & 250 \\
Intraop Cl & 5 & 2 & 60 \\
Cl fitting & 7 & 3 & 57 \\
\hline
\end{tabular}

$A B R$ auditory brainstem response testing, $A-A B R$ automated $A B R, V E M P$ vestibular evoked myogenic potential, VNG videonystagmography, $v H I T$ video head impulse test, $C D P$ computerized dynamic posturography, $O A E$ optoacoustic emission testing, Intraop $\mathrm{Cl}$ intraoperative cochlear implant measurement

seek treatment or screening based on audiological measurements. Safety is critical not only for patients, but also for audiologists. It is essential to take the necessary precautions to protect both of them while performing the audiovestibular tests. At this point, the results of our study may be important.

Overall, a decrease of almost $80 \%$ was encountered in the number of audiology tests within one during the Covid-19 pandemic. Governmental regulations, social isolation rules, and patient reservations might be associated with this decreases to go to medical centers. However, a significant increase was encountered in the number of patients who applied for tinnitus management. Emotional impact of the pandemic might have played a role in this matter $[3,4]$.

In our experience, there are several risk factors associated with contamination in an audiology setting. First, the test cabins in audiology departments are small in size. The patient and audiologist will have to talk to each other in a short distance, which may cause contamination potentially by virus-loaded droplets. This is mainly true in speech audiometry areas and when lip reading is needed. Speech and the possibility of sneezing may lead to contamination or dissemination of infection [5].

Surgical masks can be protective against droplets. However, N95 masks should be used when the likelihood of Covid-19 infection increases as in the intensive care units and when there is close contact with a Covid-19-positive person. In the study, the optical sizer intake port was placed $15 \mathrm{~cm}$ away from the nares. The distance specified in the study is considered to be similar to the microphone distance from the mouth used in speech audiometry. Accordingly, surgical masks can facilitate sufficient protection unless the audiologist or patient sneezes during the test. If one of them sneezes, it is recommended to disinfect the room and microphone unless the sneezer was wearing an N95 mask. It should be remembered that a surgical mask acts as a low pass filter and leads to $12 \mathrm{~dB}$ HL change at speech reception test (SRT) [6]. The overall effect of a mask on a patient with hearing impairment will be more significant [7].

The second major risk is related with vomiting of the patient during vestibular tests. Vomiting may be accompanied by forced breathing, both of which can increase the risk of contamination [8]. It is suggested that patients may have gastrointestinal involvement due to the presence of Covid-19 virus particles in the stool [9], and this may cause possible transmission with vomiting, although this issue needs confirmation.

There is a risk of transmission through audiological equipment. There are some studies related to the viability of viral particles on inert surfaces [10]. Although the transmission risk is still unknown, the frequently touched surfaces should be cleaned and disinfected. These surfaces are desks, door handles, light switches, counters, handles, desks, phones, keyboards, toilets, taps, and sinks. We applied disinfection to the areas in our clinic 3 times a day [11].

World Health Organization (WHO) and national guides can be used for general considerations [12]. But 
the audiology associations guidelines specific for the audiology clinics are also very helpful [13-15].

\section{Conclusion}

It is possible to perform audiovestibular tests during the Covid-19 pandemic by wearing necessary protective equipment and disinfecting the potential surfaces. Vomiting during vestibular tests, uncovering the nose and mouth for lip reading, and small-sized test cabins are the main risk factors of contamination in the audiology clinics.

\section{Abbreviations}

ABR: Auditory brainstem response; CDP: Computerized dynamic posturography; Cl: Cochlear implant; dB: Decibel; ENT: Ear, nose, throat; HL: Hearing level; PCR: Polymerase chain reaction; SRT: Speech reception test; VEMP: Vestibular evoked myogenic potentials; VHIT: Video head impulse test: VNG: Videonystagmography; WHO: World Health Organization

\section{Acknowledgements}

Not applicable.

\section{Authors' contributions}

OY: design of the work. DB: analysis. HY: interpretation of the data. BÖM: drafted the work. All authors have read and approved the manuscript; also, they took care of patients with personal protective device usage during the pandemic period, and all of them contributed to the paper in all phases.

\section{Funding}

This research received no specific grant from any funding agency, commercial or not-for-profit sectors.

\section{Availability of data and materials}

Not applicable.

\section{Ethics approval and consent to participate}

The authors assert that all procedures contributing to this work comply with the ethical standards of the relevant national and institutional guidelines on human experimentation and with the Helsinki Declaration of 1975, as revised in 2008. Ethics committee approval was received for this study from the ethics committee of Istanbul Medipol University on June 26, 2020, with decision no.: 5070 and number 10840098-604.01.01-E.7837. Because the authors used retrospective data, they did not take consent to participate from patients.

\section{Consent for publication}

Not applicable.

\section{Competing interests}

The authors declare that they have no competing interests.

Received: 13 August 2020 Accepted: 8 January 2021

Published online: 25 January 2021

\section{References}

1. Wilder-Smith A, Freedman DO (2020) Isolation, quarantine, social distancing and community containment: pivotal role for old-style public health measures in the novel coronavirus (2019-nCoV) outbreak. J Travel Med. https://doi.org/10.1093/jtm/taaa020

2. Jin Y, Yang H, Ji W, Wu W, Chen S, Zhang W, Duan G (2020) Virology, epidemiology, pathogenesis, and control of covid-19. Viruses. https://doi. org/10.3390/v12040372

3. Alpini D, Cesarani A (2006) Tinnitus as an alarm bell: stress reaction tinnitus model. https://doi.org/10.1159/000090488

4. Hinton DE, Chhean D, Pich V, Hofmann SG, Barlow DH (2006) Tinnitus among Cambodian refugees: relationship to PTSD severity. J Trauma Stress. https://doi.org/10.1002/jts.20138
5. Workman AD, Jafari A, Welling DB, Varvares MA, Gray ST, Holbrook EH, Scangas GA, Xiao R, Carter BS, Curry WT, Bleier BS (2020) Airborne aerosol generation during endonasal procedures in the era of COVID-19: risks and recommendations. Otolaryngology - Head Neck Surg (United States). https://doi.org/10.1177/0194599820931805

6. Goldin A, Weinstein BE, N. S (2020) How do medical masks degrade speech reception?

7. Atcherson SR, Mendel LL, Baltimore WJ, Patro C, Lee S, Pousson M, Spann MJ (2017) The effect of conventional and transparent surgical masks on speech understanding in individuals with and without hearing loss. J Am Acad Audiol. https://doi.org/10.3766/jaaa.15151

8. Li LQ, Huang T, Wang YQ, Wang ZP, Liang Y, Huang TB, Zhang HY, Sun W, Wang Y (2020) COVID-19 patients' clinical characteristics, discharge rate, and fatality rate of meta-analysis. J Med Virol. https://doi.org/10.1002/jmv.25757

9. Van Doremalen N, Bushmaker T, Morris DH, Holbrook MG, Gamble A, Williamson BN, Tamin A, Harcourt JL, Thornburg NJ, Gerber SI, Lloyd Smith JO, De Wit E, Munster VJ (2020) Aerosol and surface stability of SARSCoV-2 as compared with SARS-CoV-1. N Engl J Med. https://doi.org/10.1056/ NEJMC2004973

10. CDC (2020) Center for disease control and prevention https://www.cdc.gov/ coronavirus/2019-ncov/prevent-getting-sick/prevention.html

11. WHO (2020) Interim guidance (2020 mar) infection prevention and control during health care when COVID-19 is suspected https://www.who.int/ publicationsdetail/infectionprevention-and-control-during-health-care-whennovel-coronavirus-(ncov)infection-issuspected-20200125

12. ASHA (2020) Audiology service delivery considerations in health care during coronavirus COVID-19 https:/www.asha.org/aud/Audiology-Service-DeliveryConsiderations-in-Health-Care-During-Coronavirus-COVID-19

13. British Academy of Audiology (2020) Covid-19 guidance documents https:// www.baaudiology.org/professional-information/covid-19/ covidguidancedocuments/

14. OSHA (2020) Occupational safety and health administration (2020) United States Department of Labor www.osha.gov/lawsregs/regulations/ standardnumber/1910/1910.132

15. Rizk HG, Strange C, Atallah S, Massingale S, Clendaniel R (2020) Coronavirus disease 2019 return to work guidance and recommendations for vestibular clinicians. Ear Hear. https://doi.org/10.1097/aud.0000000000000903

\section{Publisher's Note}

Springer Nature remains neutral with regard to jurisdictional claims in published maps and institutional affiliations.

\section{Submit your manuscript to a SpringerOpen ${ }^{\circ}$ journal and benefit from:}

- Convenient online submission

- Rigorous peer review

- Open access: articles freely available online

- High visibility within the field

- Retaining the copyright to your article

Submit your next manuscript at $>$ springeropen.com 